\title{
Application of Online Learning within Education of Future Engineers during the Covid-19 Pandemic
}

\author{
https://doi.org/10.3991/ijep.v12i1.25009 \\ Svetlana B. Seryakova ${ }^{1(\varpi)}$, Xiaowen Zhang ${ }^{2}$, Olga V. Galustyan ${ }^{2}$, \\ Nailya N. Askhadullina ${ }^{3}$, Tatyana V. Pushkareva ${ }^{1}$, Elena V. Zvonova ${ }^{1}$ \\ ${ }^{1}$ Moscow Pedagogical State University, Moscow, Russia \\ ${ }^{2}$ Southern Federal University, Rostov-on-Don, Russia \\ ${ }^{3}$ Elabuga Institute of Kazan Federal University, Kazan, Russia \\ svetlana.b.seryakova@gmail.com
}

\begin{abstract}
The article is devoted to application of online learning within education of future engineers during the Covid-19 pandemic. Online learning challenges traditional education mode due to the rapid development of modern information technologies. The problem of online education is relevant in connection with urgent transfer of education to the online format during the COVID-19 pandemic. Application of online learning within engineering education meets the needs of new social situation, it provides updating teaching mode, teaching content, teaching concept, teaching level, and testing means. Online learning is characterized by changes of teacher's role, student's status, media's role, and teaching process. The authors conclude that practical applicability of data visualization combined within online education of future engineers leads to the development of their professional competence. Online learning provides new tools for engineering teaching and becomes an important force for improving future engineers' knowledge, skills and learning efficiency.
\end{abstract}

Keywords - online learning, information technology, data visualization, students, future engineers

\section{Introduction}

Education is a kind of social phenomenon, which is produced for the needs of human production, labor skills and life experience. Modernization of education means development of human resources and training of qualified personnel that provides rise of economy. Scientists consider [2, 10, 16] that engineering education is the most important component of technological modernization of national economy of every country. That is why today there is a serious need for engineering professionals.

Modern educational policy of preparing future engineers is connected not only with continuous application of information technologies in the field of education, but also with the situation of COVID-19 pandemic. Educational organizations work with students remotely to reduce the risks of spread of coronavirus. In this regard, all face- 
to-face classes, which included lectures, practical and even laboratory classes with virtual counterparts, were transferred to the online environment. The problem of online education is now very relevant in connection with the urgent transfer of education to the online format during the COVID-19 pandemic [1, 4, 12].

Application of online learning within education of future engineers during the Covid-19 pandemic provides new tools for engineering teaching and becomes an important force for improving future engineers' knowledge, skills and learning efficiency. According to $[6,17]$ online learning realizes theory and practice of teaching optimization through the design, development, evaluation, management of teaching and learning process and teaching resources by means of modern information technologies. Application of online learning is also connected with analyzing of data visualization technology in teaching.

Application of online learning meets the needs of the new social situation, it provides updating teaching mode, teaching content, teaching concept, teaching level, and testing means. Teaching means and methods meet the requirements of the development of information technologies, construction and strengthening of digital teaching environment such as campus network and multimedia classroom. Application of online learning within education of future engineers during the Covid-19 Pandemic promotes development of all aspects of engineering education.

\section{Methodology}

\subsection{Impact on teaching mode}

Practice of application of online learning within engineering education has proved that introduction of modern information technologies doe not only improve teaching methods and means, but also changes the teaching mode of engineering education and speeds up gaining knowledge and skills. During the Covid-19 pandemic most of the universities have created multimedia classrooms. The teaching mode has been changed greatly $[8,13]$. Amount of information which is obtained by students during the lesson has increased significantly. Modern teaching mode has received the following characteristics:

- change of teacher's role,

- change of student's status,

- change of media's role,

- change of teaching process.

Online learning within engineering education has a wide coverage of many disciplines, that is why teaching mode is not limited to one pattern. Combination of network teaching and distance teaching promotes the development of online learning within engineering education. 


\subsection{Impact on teaching content}

Internet has become a feasible and demanding tool for providing a high quality of engineering education. It does not only change the way of acquiring knowledge, but also changes the nature of learning content and means. Most of the curriculum contents are organized according to the knowledge of various disciplines. In fact, it is done for achieving compression and selection of engineering curriculum content. In today's knowledge explosion, it is no longer important to instill ready-made knowledges to students, but to reveal structure of knowledge for students, to select highquality systematic knowledge, and to organize it according to students' cognitive structure.

Online learning within engineering education requires changing of the teaching course of knowledge transfer and knowledge replication into the course of knowledge operation and knowledge creation because of increasing prominent importance of information resources. Engineering curriculum should be regarded as changing and updating teaching medium constantly instead of a fixed teaching purpose, and the whole engineering education process should be regarded as an informational system. Renewal of engineering teaching content will expand students' knowledge greatly. Students do not accept any longer a single knowledge, but a knowledge system of various disciplines. Society pays more attention to the students' ability for selfunderstanding, self-innovation, and self-learning from the perspective of the information age. Therefore, updating of teaching content of engineering education will improve students' ability to adapt to the needs of society [3].

\subsection{Impact on learning styles}

Lifelong education has become the need of modern society with the advent of the new century. Online learning within engineering education based on advanced Internet and multimedia technologies has made a great progress compared with the previous education mode to get education at any time and any place. Mobile Internet technologies which are based on the combination of mobile data communication technologies and Internet can also solve this problem. This is also the reason why new concepts, new ideas and new technologies such as flipped classroom, MOOCs, micro classes, cloud computing, big data and WeMedia are emerging constantly. Online learning creates a network environment for students where students can browse online learning website to broaden their horizons at any time. At the same time, online learning within engineering education also attaches importance to students' independent activities, makes possible to conduct explorations, changes teaching and learning methods, and stimulates students' initiatives and creativity in learning $[9,14]$. 


\section{$3 \quad$ Materials and methods}

\subsection{Concept of data visualization}

Data visualization is becoming an important medium for people to understand the world during the recent years. Students' learning tools are no longer limited to books because of the popularity of smart phones, tablet computers and other personal devices. At the same time, education of future engineers needs to operate skills, so that classroom interaction is important particularly $[5,7,15]$.

During the era of big data, it is important to integrate data visualization technology with the network intelligent equipment as the basic tool of online learning within engineering education. It is necessary to promote the development of online teaching, to enhance online interaction and to improve efficiency of online learning continuously. Application of data visualization of online learning within engineering education means visualizing of teaching content and data and generating them into the process of online teaching; it optimizes the whole teaching process in all aspects and activities.

\subsection{Visualization process}

The best way for optimization of online learning within engineering education is to present classroom data as a visual result. This process takes such six steps as data collection, data preparation, preprocessing, analysis, mining, and visualization. Although all kinds of online technologies are based on network intelligent device which are popularized and applied in teaching, there is still no technical tool that can integrate processing and application of different types of classroom data. The application of online visualization is still scattered in various technical tools.

Application of visualization technology for online learning within engineering education includes such aspects as visualization of teaching content and of teaching process [11, 17]. Visualization of teaching content can be realized within spatial learning strategies and technologies such as concept, mind and cognitive maps. Visualization of teaching process means representing each data item in database as a single element, expressing each attribute value of data in the form of multidimensional data, observing, analyzing data from different dimensions. Visualization of teaching process includes such three basic processes as obtaining classroom data, presenting visualization results, and adjusting feedback. The sequence of three basic processes can be adjusted flexibly according to teaching practice. Continuous application of these processes can promote a virtuous circle of teaching improvement.

\section{$4 \quad$ Results}

Our study was conducted at Southern Federal University (Russian Federation, Rostov-on-Don) in 2020. We involved 179 participants of this university in the study of application of online tools within education of future engineers. Age range of the 
participants was from 20 to 22 years. All of them were students of the direction of training "Software engineering" of such specialties as "System Analysis and Management" and "Management in Technical Systems". The total number of students was 179 (91 participants were in experimental group, control group included 88 participants).

Education of future engineers in control group included lectures and seminars by means of platform Microsoft Teams. Teachers used traditional presentations during lectures and seminars. Traditional teaching was transferred to the online environment and in fact there was no difference from the previous one except for the way of transmitting information. Students studied at home; classes were also conducted according to the schedule.

Realization of experimental work in experimental group conducted according to the program of application of online learning within education of future engineers. Program of application of online learning within education of future engineers included using data visualization technology. University teachers presented information for students with the support of modern education technology such as data visualization technology that provided high artistic quality to learning content and intensification of students' knowledge. They optimized the teaching process through the analysis of students' learning data and provided personalized guidance for students.

We used such tools as Datawrapper and Google Charts for data visualization. Since first-year students were involved into the experiment, they had only basic programming knowledge. That is why the choice of these tools related to that their application did not require special knowledge and skills of programming. Besides, Datawrapper and Google Charts tools suited for educational needs, they were free of charge and had friendly interface. These tools were used by teachers for preparing for lectures and practical classes which were conducted in Teams. Students also used the same tools to prepare for practical classes. Datawrapper browser-based data visualization tool was suitable for educational purposes, it was used for working with spreadsheets and databases, for creating charts and infographics, and etc.

We discovered the following advantages of Datawrapper:

- it made easy to depict different kinds of data using colors, fonts, and shapes;

- it had 19 responsive and interactive chart types;

- it did not require coding;

- it made it possible to copy and to paste data from web, Excel or data sheets, to download files in CSV / XLS format, to export charts in PNG, SVG or PDF format;

- graphs, maps and other graphics were automatically saved after they were created;

- it was compatible with all operating systems;

- it allowed to edit diagrams easily.

We also used Google Charts which also was suitable for educational purposes (for creating visual data, using data sheets, Google spreadsheet integration, animation, and etc).

We discovered the following advantages of Google Charts tool: 
- it was easy to use;

- it integrated Google Charts with other Google products easily;

- it made it easy to embed diagrams on websites and social networks;

- it provided picture gallery and many templates;

- it displayed data on websites quickly and in a real time;

- it provided an interactive information control panel.

Students of experimental group deepened their understanding of disciplines and enhanced interactivity and relevance of knowledge through the visualization of inquiry data. They conducted self-reflection and formed their own learning path map according to the teachers' feedback on their learning process. All the students of experimental group made notes in their self-reflection digital diaries. They used concept maps, mind maps, cognitive maps within their learning.

During the experimental work in experimental group great attention was paid to "visual" teaching interaction. "Visual" teaching interaction and the dynamic generation of teaching were emphasized that promoted continuous improvement of learning process and supported online classroom management. It innovated the traditional online class interaction, promoted interaction between teachers and students, and promoted application of teacher information and data technology to a great extent. It was particularly important for vocational education of future engineers which focused on online class interaction formation of practical skills.

The aim of application of online tools within education of future engineers was to develop their professional competence. Professional competence of future engineers included such components as technical, research, project, and analytical one.

Technical component of professional competence of future engineers was characterized by willingness to apply the basic methods and tools of software development; ability to use operating systems, network technologies, software interface, development tools, database management systems; readiness and ability to use various software development technologies.

Research component of professional competence of future engineers was expressed in ability and readiness for using methods and tools for researching objects of professional activity; ability and willingness for substantiating the design decisions, setting up and carrying out experiments, checking their correctness and efficiency; ability and readiness for preparing scientific reports on the results of performed work, publishing research results in the form of articles and reports at scientific and technical conferences.

Project component of professional competence of future engineers was characterized by ability and readiness in modeling, analysis and using of formal methods of software design; ability in assessing capacitive complexity of software; ability and willingness in reading, understanding, and highlighting the main idea of the read source code and documentation; ability in creating software interfaces.

Analytical component of professional competence of future engineers was expressed in ability and readiness for performing an initial assessment of the degree of difficulty, risks, costs and form a work schedule; ability for preparing commercial proposals with solution options. 
Practical implementation of the research process of was carried out in the form of an analysis based on Likert scale. The results of the conducted study on application of online tools within education of future engineers are presented in Table 1 and Table 2.

Table 1. Level of professional competence in the experimental and control groups at the beginning of the experiment

\begin{tabular}{|c|c|c|c|c|c|c|}
\hline \multirow[b]{2}{*}{ Professional competence } & \multicolumn{3}{|c|}{ Experimental group } & \multicolumn{3}{|c|}{ Control group } \\
\hline & $\begin{array}{c}\text { Low level, } \\
\%\end{array}$ & $\begin{array}{l}\text { Middle } \\
\text { level, \% }\end{array}$ & $\underset{\%}{\text { High level, }}$ & $\begin{array}{c}\text { Low level, } \\
\%\end{array}$ & $\underset{\%}{\text { Middle level, }}$ & $\underset{\%}{\text { High level, }}$ \\
\hline Technical component & 40.7 & 38.5 & 20.8 & 39.8 & 38.6 & 21.6 \\
\hline Research component & 54.9 & 28.6 & 16.5 & 37.5 & 39.8 & 22.7 \\
\hline Project component & 42.8 & 34.1 & 23.1 & 40.9 & 30.7 & 28.4 \\
\hline Analytical component & 56.0 & 29.7 & 14.3 & 44.3 & 34.1 & 21.6 \\
\hline
\end{tabular}

Table 2. Level of professional competence in the experimental and control groups at the end of the experiment

\begin{tabular}{|l|c|c|c|c|c|c|}
\hline \multirow{2}{*}{ Professional competence } & \multicolumn{3}{|c|}{ Experimental group } & \multicolumn{3}{c|}{ Control group } \\
\cline { 2 - 7 } & $\begin{array}{c}\text { Low level, } \\
\boldsymbol{\%}\end{array}$ & $\begin{array}{c}\text { Middle level, } \\
\boldsymbol{\%}\end{array}$ & $\begin{array}{c}\text { High level, } \\
\boldsymbol{\%}\end{array}$ & $\begin{array}{c}\text { Low level, } \\
\boldsymbol{\%}\end{array}$ & $\begin{array}{c}\text { Middle level, } \\
\boldsymbol{\%}\end{array}$ & $\begin{array}{c}\text { High level, } \\
\boldsymbol{\%}\end{array}$ \\
\hline Technical component & 12.1 & 37.4 & 50.5 & 42.1 & 38.6 & 19.3 \\
\hline Research component & 8.8 & 26.4 & 64.8 & 34.1 & 43.2 & 22.7 \\
\hline Project component & 9.9 & 22.0 & 68.1 & 33.0 & 37.5 & 29.5 \\
\hline Analytical component & 5.5 & 27.5 & 67.0 & 42.0 & 36.4 & 21.6 \\
\hline
\end{tabular}

The results of experimental work on application of online tools within education of future engineers for the development of professional competence in control and experimental groups revealed that in the experimental group the level of professional competence is higher than in the control group, that proved the effectiveness of the experimental work.

\section{Conclusions}

Rapid development of modern educational technologies and information technologies has a great impact on online learning within education of future engineers. Furthermore, situation of COVID-19 pandemic forced to find optimal methods of online education. Application of online learning within engineering education provided updating teaching mode, teaching content, teaching concept, teaching level. It led to application of data visualization technology within education of future engineers. Data visualization technology is evolving constantly. It covers the scope of scientific visualization and information visualization gradually. The explored practical applicability of data visualization combined within online education of future engineers proves its effectiveness. University teachers provide analyzing data of supporting students' deep learning, using information technology to present teaching content better and optimizing teaching process. 


\section{Acknowledgment}

The study was supported by RFBR, research project N 19-013-00822.

\section{$7 \quad$ References}

[1] Agarwal, A., Sharma, S., Kumar, V., \& Kaur, M. (2021). Effect of E-learning on public health and environment during COVID-19 lockdown. Big Data Mining and Analytics, 4(2), 104-115. https://doi.org/10.26599/BDMA.2020.9020014

[2] Appiah-Kubi, P., \& Annan, E. (2020). A review of a collaborative online international learning. International Journal of Engineering Pedagogy, 10(1), 109-124. https://doi.org/ 10.3991/ijep.v10i1.11678

[3] Billon, M., Crespo, J., \& Lera-Lopez, F. (2021). Do educational inequalities affect Internet use? An analysis for developed and developing countries. Telematics and Informatics, 58. https://doi.org/10.1016/j.tele.2020.101521

[4] Choudrie, J., Banerjee, S., Kotecha, K., Walambe, R., Karende, H., \& Ameta, J. (2021). Machine learning techniques and older adults processing of online information and misinformation: A covid 19 study. Computers in Human Behavior, 119. https://doi.org/10.1016/ j.chb.2021.106716

[5] Deng, R., \& Benckendorff, P. (2021). What are the key themes associated with the positive learning experience in MOOCs? An empirical investigation of learners' ratings and reviews. International Journal of Educational Technology in Higher Education, 18(1). https://doi.org/10.1186/s41239-021-00244-3

[6] Efthymiou, L., \& Zarifis, A. (2021). Modeling students' voice for enhanced quality in online management education. International Journal of Management Education, 19 (2). https://doi.org/10.1016/j.ijme.2021.100464

[7] Escamilla-Fajardo, P., Alguacil, M., \& López-Carril, S. (2021). Incorporating TikTok in higher education: Pedagogical perspectives from a corporal expression sport sciences course. Journal of Hospitality, Leisure, Sport and Tourism Education, 28. https://doi.org/ 10.1016/j.jhlste.2021.100302

[8] Gallego Sánchez, M. D. C., De-Pablos-Heredero, C., Medina-Merodio, J. , RobinaRamírez, R., \& Fernandez-Sanz, L. (2021). Relationships among relational coordination dimensions: Impact on the quality of education online with a structural equations model. Technological Forecasting and Social Change, 166. https://doi.org/10.1016/j.techfore.202 $\underline{1.120608}$

[9] Galustyan, O. V., Borovikova, Y. V., Polivaeva, N. P., Kodirov, B. R., \& Zhirkova, G. P. (2019). E-learning within the field of andragogy. International Journal of Emerging Technologies in Learning, 14(9), 148-156. https://doi.org/10.3991/ijet.v14i09.10020

[10] Galustyan, O. V., Solyankin, A. V., Skripkina, A. V., Shchurov, E. A., Semeshkina, T. V., \& Ledeneva, A. V. (2020). Application of blended learning for formation of project competence of future engineers. International Journal of Engineering Pedagogy, 10(3), 106113. https://doi.org/10.3991/ijep.v10i3.12251

[11] Idnani, D., Kubadia, A., Jain, Y., \& Churi, P. (2021). Experience of conducting online test during COVID-19 lockdown: A case study of NMIMS university. International Journal of Engineering Pedagogy, 11(1), 49-63. https://doi.org/10.3991/ijep.v11i1.15215

[12] Karakose T, Yirci R, Papadakis S. (2021). Exploring the Interrelationship between COVID-19 Phobia, Work-Family Conflict, Family-Work Conflict, and Life Satisfaction 
among School Administrators for Advancing Sustainable Management. Sustainability. 13(15):8654. https://doi.org/10.3390/su13158654

[13] Muhammad, N., \& Srinivasan, S. (2021). Online education during a pandemic - adaptation and impact on student learning. International Journal of Engineering Pedagogy, 11(3), 7183. https://doi.org/10.3991/ijep.v11i3.20449

[14] Obukhova, L. A., Galustyan, O. V., Baklanov, I. O., Belyaev, R. V., Kolosova, L. A., \& Dubovitskaya, T. V. (2020). Formation of organizational competence of future engineers by means of blended learning. International Journal of Engineering Pedagogy, 10(2), 119127. https://doi.org/10.3991/ijep.v10i2.12047

[15] Petelin, A. S., Galustyan, O. V., Prosvetova, T. S., Petelina, E. A., \& Ryzhenkov, A. Y. (2019). Application of educational games for formation and development of ICT competence of teachers. International Journal of Emerging Technologies in Learning, 14(15), 193-201. https://doi.org/10.3991/ijet.v14i15.10572

[16] Polo, M., Quirós, E., \& Felicísimo, Á. M. (2021). Geoengineering education for management of geospatial data in university context. Journal of Surveying Engineering, 147(2). https://doi.org/10.1061/(asce)su.1943-5428.0000349

[17] Vasodavan, V., DeWitt, D., Alias, N., \& Noh, M. M. (2021). E-moderation skills in discussion forums: Patterns of online interactions for knowledge construction. Pertanika Journal of Social Sciences and Humanities, 28(4), 3025-3045. https://doi.org/10.47836/pjs $\underline{\text { sh.28.4.30 }}$

\section{Authors}

Svetlana B. Seryakova is Professor of Department of Social Pedagogy and Psychology, Faculty of Pedagogy and Psychology, Moscow Pedagogical State University, Moscow, Russia.

Xiaowen Zhang is Postgraduate, Faculty of Management, Southern Federal University, Rostov-on-Don, Russia.

Olga V. Galustyan is Professor of the Department of Education and Pedagogical Sciences, Academy of Psychology and Pedagogy of Southern Federal University, Rostov-on-Don, Russia.

Nailya N. Askhadullina is Senior Lecturer of Department of Pedagogic of Elabuga Institute of Kazan Federal University, Kazan, Russia.

Tatyana V. Pushkareva is Professor of Department of Social Pedagogy and Psychology, Faculty of Pedagogy and Psychology, Moscow Pedagogical State University, Moscow, Russia.

Elena V. Zvonova is Associate Professor of Department of Social Pedagogy and Psychology, Faculty of Pedagogy and Psychology, Moscow Pedagogical State University, Moscow, Russia.

Article submitted 2021-06-23. Resubmitted 2021-08-07. Final acceptance 2021-08-08. Final version published as submitted by the authors. 